\title{
To Study the Levels of Potassium and Creatinine in Patients of Suspected Acute Myocardial Infarction (AMI)
}

\author{
Mritunjay Kumar Mishra ${ }^{1, *}$, Snehita Prasad ${ }^{2}$, Kajal Kumari Valand ${ }^{3}$ \\ 1Department of Biochemistry, SBKSMI and RC, Sumandeep Vidyapeeth University, Gujarat, INDIA. \\ ${ }^{2}$ Nursinbhai Patel Dental College and Hospital, Sankalchand Patel University, Gujarat, INDIA. \\ ${ }^{3}$ Department of Pharmacology, SBKSMI and RC, Sumandeep Vidyapeeth University, Gujarat, INDIA.
}

\begin{abstract}
Background: Acute myocardial infarction is one of the leading causes of morbidity and mortality across the world. Serum Potassium and creatinine levels changes in cardiac chest pain and non-cardiac chest pain but have not been studied extensively and there is a paucity of information in the literature in this regard. Scanty information is available in the literature about the prognostic value of serum Potassium and Creatinine in Chest pain. Hence this study was undertaken to estimate the concentrations of serum potassium and creatinine in AMI patients. Materials and Methods: A total of 200 patients were enrolled from the Cardiac OPD of Dhiraj Hospital. 100 were cases and 100 were controls. The levels of creatinine were measured by EM-200 at Dhiraj Hospital and levels of Potassium were measured at Nulyte analyzer. Results: The mean levels of potassium and creatinine were high in cases $(4.27 \pm 0.56$ and $0.99 \pm 0.53)$ in comparison with respective control $(4.30 \pm 0.92$ and $0.87 \pm 0.23)$ and there was a significant difference between levels of potassium and serum creatinine $(P<0.001)$. Conclusion: The levels of potassium could be useful for prediction of mortality of myocardial infarction.
\end{abstract}

Key words: Cardiac chest pain, Myocardial infarction, Creatinine, Potassium Acute myocardium Infarction, Non-cardiac chest pain.

\begin{tabular}{r} 
Article Information \\
\hline Received: 04-05-2021 \\
Revised : 29-05-2021 \\
Accepted: 10-07-2021 \\
\hline Correspondence \\
Mr. Mritunjay Kumar Mishra \\
Tutor, Department of Biochemistry, SBKSMI \\
and RC, Vadodara-391760, Gujarat, INDIA. \\
Phone: +91-8469635257 \\
E-mail: mritunjaymishra007@gmail.com
\end{tabular}

\section{INTRODUCTION}

Coronary artery disease leading to Myocardial Infarction (MI) is the leading cause of sudden cardiac death. Ischemic heart disease is more prevalent in patients with renal dysfunction than in the general population. Previousstudiesshowed anincreased riskofcardiovascular disease and adverse cardiovascular outcomes in patients with renal insufficiency. ${ }^{1}$ Cardiovascular disease is one of the leading causes of morbidity and mortality across the world. World Health Organization (WHO) has declared cardiovascular disease as a modern

\begin{tabular}{|l|c|}
\hline \multicolumn{2}{|c|}{ Access this article online } \\
\hline $\begin{array}{l}\text { Website: } \\
\text { www.jcramonline.com }\end{array}$ & Quick Response code \\
\hline DOI: & \\
10.5530/jcram.1.1.3 & \\
& \\
\hline
\end{tabular}

epidemic. ${ }^{2}$ Creatine release was compared in various conditions of muscle damage: acute Myocardial Infarction (AMI), unstable angina, and cardiac surgery. After AMI, serum, and urine creatine concentrations increased transiently. Potassium homeostasis is critical to prevent adverse events in patients with cardiovascular disease. Several studies have demonstrated a relationship between low serum potassium levels, usually less than $3.5 \mathrm{mEq} / \mathrm{L}$, and the risk of ventricular arrhythmias in patients with Acute Myocardial Infarction (AMI). ${ }^{3}$

Based on these studies, experts and professional societies have recommended maintaining potassium levels between 4.0 and $5.0 \mathrm{mEq} / \mathrm{L}$, or even 4.5 to $5.5 \mathrm{mEq} / \mathrm{L}$, in AMI patients. ${ }^{3}$

Potassium disturbances are one of the most common electrolyte abnormalities. The role of potassium disturbances in the setting of MI has been studied, with a higher frequency of ventricular arrhythmias observed for low potassium levels (typically $<3.5 \mathrm{mmol} / \mathrm{L}$ ). ${ }^{4}$ 
Baseline renal function is a potent independent risk factor for adverse events after acute myocardial infarction (MI). Worsening renal function (WRF) has been shown to influence outcomes in the heart failure population, but its impact on cardiovascular risk in the post-MI period has not been well defined. For assessment of the prognostic importance of WRF by using the serum creatinine. ${ }^{5}$ Looking into the above consequences the study was planned to evaluate the level of Serum potassium and creatinine in patients withan ischemic type of chest pain.

\section{MATERIALS AND METHODS}

The present study is a type of case-control study, which was carried out in the department of biochemistry, Smt. B.K. Shah Medical Institute and Research center, Sumandeep Vidyapeeth Vadodara, Gujarat after getting ethical approval from Institutional ethical committee (Approval No: SVIEC/ON/MED1/Ph.D./18015). A total of 200 subjects having the age gropu of 30-70 years were enrolled from the cardiac care unit (CCU) from Dhiraj Hospital, Sumandeep Vidyapeeth, Vadodara, Gujarat. Out of these, 100 with cardiac chest pain (CCP) comprised as case group and 100 with non-cardiac chest pain as controls. The diagnosis was confirmed by Cardiologist review, which was based upon patient details such as clinical history, ECG, and cardiac biomarker (above $99^{\text {th }}$ percentile of troponin I).

Patients with diabetes mellitus, chronic muscle disease, renal disease, autoimmune disease, arthritis, any inflammatory disease, recent surgery, and any other disease except AMI were excluded from the study.

Approximately $3 \mathrm{ml}$ blood sample was taken in plain vials from both the subjects i.e., CCP and NCCP under all aseptic precautions. Sample was centrifuged at 3000 RPM for $15 \mathrm{~min}$ to get serum sample. The levels of creatinine were measured by EM-200 at Dhiraj Hospital and levels of Potassium were measured at Nulyte analyzer. Patient confidentiality was maintained at every level.

\section{Statistical Analysis}

Data were analyzed with the help of the software program Statistical Package for Social Sciences (SPSS version 21, Chicago). The statistical differences between cases and control were determined by student independent sample $t$-test. A $p$-value is less than 0.05 $(P \leq 0.05)$ was considered as significant difference.

\section{RESULTS}

Following results were obtained from the study.

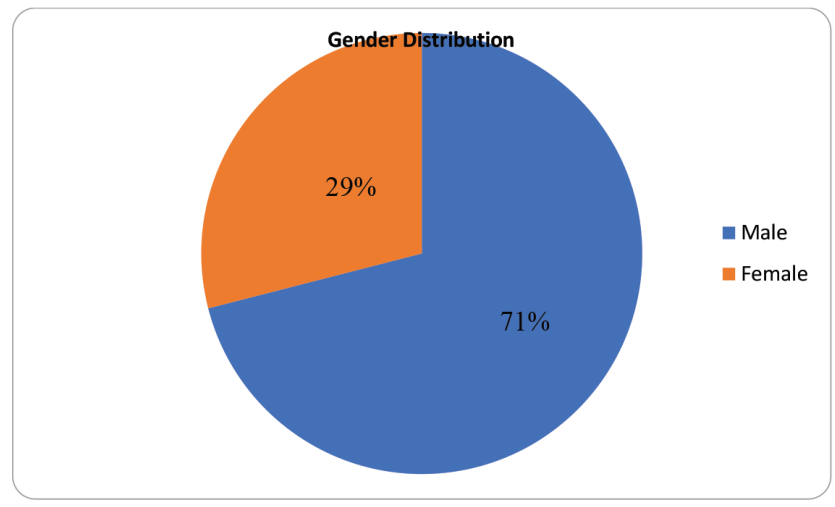

Figure 1: Gender Distribution of Patients.

Table 1: Showing statistical changes in the mean levels of creatinine and potassium levels in Cases and controls.

\begin{tabular}{ccccc}
\hline Parameter & $\begin{array}{c}\text { Cardiac } \\
\text { chest pain } \\
\text { (Cases) }\end{array}$ & $\begin{array}{c}\text { Non- } \\
\text { cardiac } \\
\text { chest pain } \\
\text { (Control) }\end{array}$ & \\
\hline $\begin{array}{c}\text { Creatinine } \\
\text { (mg/dl) }\end{array}$ & Max & 0.90 & 1.1 & \\
& Min & 0.50 & 0.44 & $P<0.001$ \\
& Mean \pm SD & $0.99 \pm 0.53$ & $0.87 \pm 0.23$ & \\
Potassium & Max & 4.50 & 4.60 & \\
mEq/L & Min & 2.30 & 2.10 & \\
& Mean \pm SD & $4.20 \pm 0.56$ & $4.30 \pm 0.92$ & \\
\hline
\end{tabular}

$P<0.0001 * * *$ highly significant, $P<0.001 * *, P<0.05 *$ significant and $P>0.05 *$ not significant

The present study results revealed that $71 \%$ patients were Male and 29\% patients were female. (Figure 1)

A total of 200 subjects were enrolled in this study, comprising of 100 cases of AMI, and 100 were controls. The levels of potassium and creatinine in cardiac chest pain (Case group i.e., AMI) and non-cardiac chest pain (control group) was measured.

The data were collected for the present study was presented in the form of mean and standard deviation $(\mathrm{SD})($ Mean $\pm \mathrm{SD})$. The levels of potassium and creatinine were high in cases $(4.20 \pm 0.56$ and $0.99 \pm 0.53)$ in the comparison with respective control $(4.30 \pm 0.92$ and $0.87 \pm 0.23)$ and there was significant difference between levels of potassium and creatinine $(P<0.001)$. Table 1

\section{DISCUSSION}

Hypo- and hyperkalemia following MI are associated with increased mortality, but it is important to examine whether specific potassium intervals within the normal range also set patients at risk or appear particularly safe. ${ }^{6}$ 
It was previously shown that end-stage renal disease is a powerful predictor of death. ${ }^{7}$ Although the precise mechanisms of the interaction between impaired renal function and coronary artery disease are not clarified, the serum creatinine concentration may be a marker for concomitant cardiovascular risk factors, such as diabetes mellitus, systemic hypertension, and advanced age. However, less severe renal dysfunction, defined by a reduction in creatinine clearance or glomerular filtration rate (GFR), ${ }^{8,9}$ regardless of the underlying cause, also may lead to a significant increase in mortality after acute coronary syndromes.

Krogager et al. concluded that closer monitoring of potassium in patients with acute heart failure might improve survival. While this is possible, it is still unproven. Fluctuations in potassium levels are common in patients with AMI and CHF; therefore, alone measurement of potassium level can also predictor for mortality. ${ }^{10,11}$

To that, we have evaluated the serum potassium levels in cardiac chest pain and non-cardiac chest pain. The mean levels of serum potassium in cases are $4.20 \pm 0.56$ $\mathrm{mEq} / \mathrm{L}$ and control $4.30 \pm 0.92 \mathrm{mEq} / \mathrm{LThe}$ mean levels of potassium were significant than that of corresponding controls $(P<0.001)$. Hamid Ikram and his colleagues reported a low level of serum potassium level in hypertensive coronary heart disease. ${ }^{7}$

This may be due to the neurohormonal response in myocardial infarction reflected in the serum potassium levels and the body's attempt to maintain a normal value. Angiotensin and aldosterone blockers are often prescribed in patients with, or at risk for, CHF and counteract the hypokalaemic effects of neurohormonal activation, thus promoting hyperkalemia. A significant reduction in renal blood flow due to reduced cardiac output increase in systemic venous pressure, neurohormonal-induced vasoconstriction, or excessive use of diuretics leading to hypovolemia can all lead to severe renal hypoperfusion and acute kidney injury with an associated risk of hyperkalemia. ${ }^{8}$

Creatinine is one of the best predictor biomarkers to assess renal failure. Derangement of creatinine levels can be also seen in CVD. So, we assess the levels of serum creatinine and found mean levels of creatinine were within the normal range but it was found a significant difference between cases and controls $(P<0.001)$ Table 1.

It is common practice to withdraw ACE inhibitors when renal function deteriorates; renal artery stenosis is a common finding among patients who undergo coronary angiography and among those with heart failure. However, this policy may deprive many patients of the potential benefits of these drugs. ${ }^{8,9}$

\section{CONCLUSION}

A decrease levels of potassium could be a predictor for mortality of myocardial infarction. A serum creatinine levels are within normal range, that may be due to the renal sufficiency of patients.

The present study should be replanned with large sample size with the subgroup of myocardial infarction with and without renal insufficiency to provide a piece of evidence to this type of study.

\section{ACKNOWLEDGEMENT}

I would like to thanks Dhiraj hospital for providing me the facility needed for the research work Special thanks go to Dr. Sanket. DM Cardiology for their support and help.

\section{CONFLICT OF INTEREST}

The authors declare no conflict of interest.

\section{ABBREVIATIONS}

AMI: Acute Myocardial infarction; CCP: Cardiac Chest Pain, NCCP: Non-Cardiac Chest Pain; ECG: Electrocardiogram.

\section{REFERENCES}

1. Gibson CM, Pinto DS, Murphy SA, Morrow DA, Hobbach HP, Wiviott SD, Giugliano RP, Cannon CP, Antman EM, Braunwald E, TIMI Study Group. Association of creatinine and creatinine clearance on presentation in acute myocardial infarction with subsequent mortality. J Am Coll Cardiol. 2003;42(9):1535-43. doi: 10.1016/j.jacc.2003.06.001, PMID 14607434.

2. Park. Textbook of preventive and social medicine. 19th ed; 2007. p. 286-7.

3. Madias JE, Shah B, Chintalapally G, Chalavarya G, Madias NE. Admission serum potassium in patients with acute myocardial infarction: its correlates and value as a determinant of in-hospital outcome. Chest. 2000;118(4):90413-91311035655, doi: 10.1378/chest.118.4.904, PMID 11035655.

4. Goldberg A, Hammerman H, Petcherski S, Zdorovyak A, Yalonetsky S, Kapeliovich M, Agmon Y, Markiewicz W, Aronson D. Inhospital and 1-year mortality of patients who develop worsening renal function following acute ST-elevation myocardial infarction. Am Heart J. 2005 Aug;150(2):330-7. doi: 10.1016/j.ahj.2004.09.055, PMID 16086939

5. Bielecka-Dabrowa A, Mikhailidis DP, Jones L, Rysz J, Aronow WS, Banach M. The meaning of hypokalemia in heart failure. Int J Cardiol. 2012 Jun 28;158(1):12-7. doi: 10.1016/j.ijcard.2011.06.121. PMID 21775000.

6. Ikram H, Espiner EA, Nicholls MG. Diuretics, potassium and arrhythmias in hypertensive coronary disease. Drugs. 1986;31;Suppl 4:101-8. doi: 10.2165/00003495-198600314-00012, PMID 3732088.

7. MacDowall P, Kalra PA, O'Donoghue DJ, Waldek S, Mamtora H, Brown K. Risk of morbidity from renovascular disease in elderly patients with congestive cardiac failure. Lancet. 1998;352(9121):13-6. doi: 10.1016/s01406736(97)11060-1, PMID 9800739. 
8. Selim NA, Hmouda HT. A pilot study of cardiac troponin I in patients with acute myocardial infarction and unstable angina. Saudi Med J. 2002;23(5):526-8 8. PMID 12070573.

9. Krogager ML, Eggers-Kaas L, Aasbjerg K, Mortensen RN, Køber L, Gislason G, Torp-Pedersen C, Søgaard P. Short-term mortality risk of serum potassium levels in acute heart failure following myocardial infarction. Eur Heart $\mathrm{J}$
Cardiovasc Pharmacother. 2015;1(4, Oct):245-51. doi: 10.1093/ehjcvp/ pvv026, PMID 27418967.

10. Khosla S, Kunjummen B, Manda R, Khaleel R, Kular R, Gladson M, Razminia M, Guerrero M, Trivedi A, Vidyarthi V, Elbzour M, Ahmed A. Prevalence of renal artery stenosis requiring revascularization in patients initially referred for coronary angiography. Catheter Cardiovasc Interv. 2003;58(3):400-3. doi: 10.1002/ccd.10387, PMID 12594711.

Cite this Article : Mishra MK, Prasad S, Valand KK. To Study the Levels of Potassium and Creatinine in Patients of Suspected Acute Myocardial Infarction (AMI). J. Clin. Res. Applied Med. 2021;1(1):7-10. 